\title{
Better Ways to Study Regulatory Elephants
}

\author{
Jonathan B. Wiener, Brendon Swedlow, James K. Hammitt, Michael D. Rogers and Peter H. Sand*
}

We are grateful to the editor and reviewers for this opportunity to respond to the five essays reviewing two recent books comparing regulation in the US and Europe: The Politics of Precaution: Regulating Health, Safety, and Environmental Risks in Europe and the United States ${ }^{1}$, and The Reality of Precaution: Comparing Risk Regulation in the United States and Europe ${ }^{2}$.

* Jonathan B. Wiener is Perkins Professor of Law at Duke Law School, Professor of Environmental Policy at the Nicholas School of the Environment, and Professor of Public Policy at the Sanford School of Public Policy, at Duke University and a University Fellow of Resources for the Future (RFF). Brendon Swedlow is an Associate Professor in the Department of Political Science, at Northern Illinois University. James K. Hammitt is Professor of Economics and Decision Sciences at the Department of Health Policy and Management, Harvard School of Public Health, and visiting professor at the Toulouse School of Economics (LERNA-INRA). Michael D. Rogers is a former member of the Bureau of European Policy Advisers, at the European Commission. Peter H. Sand is lecturer in International Environmental Law at the University of Munich.

1 David Vogel, The Politics of Precaution: Regulating Health, Safety and Environmental Risks in Europe and the United States (Princeton: Princeton University Press, 2012).

2 Jonathan B. Wiener, Michael D. Rogers, James K. Hammitt, and Peter H. Sand (eds), The Reality of Precaution: Comparing Risk Regulation in the United States and Europe (Washington, D.C. and London: RFF Press/Earthscan/Routledge, 2011).

3 Maria Weimer, "It's the Politics, Stupid', Or is the Reality more Complex?", European Journal of Risk Regulation (2013), this issue.

4 David Vogel, "A More Sophisticated Approach of the Politics of Precaution", European Journal of Risk Regulation (2013), this issue.

5 Susan Rose-Ackerman, "Precaution, Proportionality, and Cost/Benefit Analysis: False Analogies", European Journal of Risk Regulation (2013), this issue.

6 Wiener, Rogers, Hammitt and Sand, The Reality of Precaution, supra note 2, Chapter 20.

7 Fabrizio Cafaggi, Book Review of The Reality of Precaution: Comparing Risk Regulation in the United States and Europe, 2(3) European Journal of Risk Regulation (2012), pp. 265-272.

8 Rose-Ackerman, "Precaution, Proportionality, and Cost/Benefit Analysis", supra note 5.

9 Adam Burgess, "Missing the Wood for the Trees", European Journal of Risk Regulation (2013), this issue.

10 Jane K. Winn, "Precautionary Schemes", European Journal of Risk Regulation (2013), this issue.

11 Burgess, "Missing the Wood for the Trees", supra note 9; Bill Durodié, "Precautionary Tales - Missing the Problem and Its Cause", European Journal of Risk Regulation, this issue.

12 Winn, "Precautionary Schemes", supra note 10.

13 Burgess, "Missing the Wood for the Trees", supra note 9.

14 Winn, "Precautionary Schemes", supra note 10.
We agree with reviewer Maria Weimer ${ }^{3}$ and with David Vogel ${ }^{4}$ that both of these books help create a research agenda for comparative studies of regulation, including studies of relative precaution, by developing theoretical explanations and a systematic basis for collecting data to test them. We also agree with reviewer Susan Rose-Ackerman ${ }^{5}$ that comparative studies of regulation should examine not only relative precaution, but more broadly the interrelationships among precaution, proportionality, impact assessment, cost-benefit analysis, and other analytic frameworks - and the value choices embedded in them. We addressed those important issues in the concluding chapter of our book ${ }^{6}$, but they certainly deserve additional inquiry. And we thank Fabrizio Cafaggi $^{7}$ for his extensive review of our book in an earlier issue of this journal; there he emphasized our book's contribution to the evolving understanding of transnational regulatory networks.

Both books undertake a descriptive comparison of relative precaution in American and European regulation over the past several decades. The two books differ in their findings, and in the evidence on which those findings rest. We thank reviewers Susan RoseAckerman $^{8}$, Adam Burgess ${ }^{9}$, and Jane K. Winn ${ }^{10}$ for acknowledging the strong empirical evidence of actual policymaking that is assembled in our book. We disagree, however, with the reviewers who allege that our book has somehow "missed the wood for the trees"11 or cast "empiricism" against "humanism"12, ostensibly because Europe yearns to define its "identity" as precautionary ${ }^{13}$ or because European regulation "feels" more precautionary ${ }^{14}$. In our view, it is a mistake to confuse rhetoric with reality, or feelings with actions, and it is an illusion to conflate political aspirations with actual policymaking. That is why we studied actual policies: to test whether they reflect the political rhetoric or not. To characterize the forest and see whether it has moved, one must examine a representative sample of the trees - which is what we have done. To compare regulatory policies, one must actually study the policies and avoid being seduced by aspirational rhetoric and symbolic politics which are not themselves evidence of real regulation. 
In this reply, we describe areas of agreement between the two books, and then examine their very different findings. In so doing, we respond to the reviewers and suggest directions for further research.

\section{Significant areas of agreement between the two books}

In what is a disappointment to some ${ }^{15}$ but welcome to others ${ }^{16}$, these two books are mainly descriptive - comparative and historical - not mainly normative; we are not, in these books, primarily evaluating which regulations are better, nor whether the precautionary principle is warranted. Both of our books examine the actual regulation of health, safety and environmental risks in the US and Europe over the last five decades. Both books appear to measure the degree of relative precaution as a combination of timing (earliness in anticipation of an uncertain or emerging risk) and stringency: our book is explicit about this approach ${ }^{17}$, and although Vogel does not articulate his measure expressly, he appears to assess his cases along the same lines (variously employing the terms stringency, risk aversion, and precaution). Both find that on several important risks, the degree of precaution in US and European policies does differ.

In addition, both books agree that regulatory systems are dynamic: they change over time. This may seem obvious, but it cuts against prominent popular and scholarly assumptions. Both books reject the view that risk regulation is determined by fixed cultures of risk, such as the familiar but simplistic stereotypes of Americans as risk-taking technological optimists and of Europeans as risk-averse technological pessimists (these stereotypes are commonplace today and historically, but are often more satirical than serious). ${ }^{18}$ Such a claim of fixed risk cultures is at odds with Vogel's account of US and European regulation having shifted over time, and with our finding of selective precautions for specific risks adopted on each side of the Atlantic. Both of our books also find that modern risk regulation is driven by modern politics, not predetermined by national "families of law"19 or ancient "legal origins" ${ }^{20}$. This move to a dynamic account contrasts with David Vogel's own prior work, in which he had argued that regulatory policies conform to distinct "national styles" ${ }^{21}$; now he finds that Europe has switched to adopt much of what he had earlier called the American style ${ }^{22}$.
Still, he continues to depict American and European risk regulation as discrete and coherent blocs that evolve as a whole, whereas our book sees them as particularized, disaggregated transnational networks of diffusion. Finally, both books recognize the value of conducting the objective, comprehensive, quantitative analysis ${ }^{23}$ found in Chapter 15 of Wiener, Rogers, Hammitt et al. ${ }^{24}$, and we agree that our different conclusions are primarily due to differences in our case selection methods.

\section{Two very different accounts of relative precaution}

In The Politics of Precaution ${ }^{25}$, Vogel makes the claim that there has been a "transatlantic shift in regulatory stringency since $1990^{\prime 26}$, from greater US precaution before 1990 to greater European precaution after 1990. He says that the likelihood of each side's regulation being "more risk averse" has itself reversed ${ }^{27}$, and in some cases there has been "a literal 'flip-flop,' with the United States and Europe switching places

15 E.g. Rose-Ackerman, "Precaution, Proportionality, and Cost/Benefit Analysis", supra note 5

16 Weimer, "'It's the Politics, Stupid"", supra note 3.

17 See Wiener, Rogers, Hammitt and Sand, The Reality of Precaution supra note 2, Chapter 20.

18 See Jonathan B. Wiener, "Whose Precaution After All? A Comment on the Comparison and Evolution of Risk Regulatory Systems", 13 Duke Journal of International and Comparative Law (2003) pp. 207-262; and Wiener, Rogers, Hammitt and Sand, The Reality of Precaution, supra note 2, Chapter 1 "The Rhetoric of Precaution".

19 Konrad Zweigert and Hein Kötz, An Introduction to Comparative Law, 3rd ed., Trans. Tony Weir (Oxford: Oxford University Press, 1998).

20 Rafael La Porta, Florencio Lopez-de-Silanes, and Andrei Shleifer "The Economic Consequences of Legal Origins", 46 Journal of ECOnomic Literature (2008), pp.435-452.

21 David Vogel, "Response to Jonathan B. Wiener and R. Daniel Kelemen", 7(2) Regulation \& Governance (2013), pp. 271-277; Vogel, "A More Sophisticated Understanding of the Politics of Precaution", supra note 4 .

22 Vogel, The Politics of Precaution, supra note 1, pp. 289-290.

23 Vogel, "Response to Jonathan B. Wiener and R. Daniel Kelemen", supra note 21; Vogel, "A More Sophisticated Understanding of the Politics of Precaution", supra note 4.

24 Brendon Swedlow, Denise Kall, Zheng Zhou, James K. Hammitt, and Jonathan B. Wiener, "A Quantitative Comparison of Relative Precaution in the United States and Europe, 1970-2004", in Wiener, Rogers, Hammitt and Sand, The Reality of Precaution, supra note 2, pp. 377-408.

25 Vogel, The Politics of Precaution, supra note 1.

$26 \mathrm{Ibid}$, p. 5.

27 Ibid, p. 2. 
with respect to the adoption of more stringent and comprehensive regulations" ${ }^{28}$. Vogel writes that "since around 1990 the American federal regulatory policy 'hare' has been moving like a 'tortoise,' while the pace of the European 'tortoise' resembles a 'hare'". ${ }^{29}$ He says this shift has been reflected in and enabled by Europe's adoption of the precautionary principle (for example in the 1992 Maastricht Treaty), in the face of US criticisms. ${ }^{30}$ To demonstrate this shift to greater European precaution, Vogel examines several cases in four detailed chapters. Vogel then argues that this transatlantic shift has been driven by three main factors on each side of the Atlantic: shifting preferences of public opinion, shifting preferences of government leaders, and shifting criteria for policy evaluation.

Our research counters Vogel's claim. In our book, The Reality of Precaution ${ }^{31}$, we studied a large array of qualitative case studies, and a quantitative measure of the relative precaution with which the US and Europe regulated 100 representative risks from 1970-2004. We find no large shift or reversal in relative transatlantic regulatory precaution. We find, instead, a complex pattern of regulation of multiple risks, with general parity between the US and Europe over the entire period since 1970, punctuated by the highly selective application of precaution to specific risks on each side - sometimes manifesting greater European precaution since 1990, but sometimes greater US precaution since 1990, and no major aggregate shift. Among our qualitative case studies Europe became more precautionary regarding genetically modified foods, toxic chemicals, and climate

$28 \mathrm{lbid}$, p. 5

29 Ibid, p. 4 (footnotes omitted).

$30 \mathrm{lbid}$, p. 9.

31 Wiener, Rogers, Hammitt and Sand, The Reality of Precaution, supra note 2 .

32 Swedlow, Kall, Zhou et al., "A Quantitative Comparison of Relative Precaution in the United States and Europe, 1970-2004", supra note 24

33 See also James K. Hammitt, Jonathan B. Wiener, Brendon Swedlow, Denise Kall, and Zheng Zhou, "Precautionary Regulation in Europe and in the United States: A Quantitative Comparison", 25(5) Risk Analysis (2005), pp. 1215-1228; Brendon Swedlow, Denise Kall, Zheng Zhou, James K. Hammitt, and Jonathan B. Wiener, "Theorizing and Generalizing about Risk Assessment and Regulation through Comparative Nested Analysis of Representative Cases", 31 Law and Policy (2009), pp. 236-269.

34 Vogel, The Politics of Precaution, supra note 1.

35 For comments on Vogel's attempts to explain his claimed shift, see Jonathan B. Wiener, "The Politics of Precaution, and the Reality", 7(2) Regulation \& Governance (2013), pp. 258-265. change, while the US became more precautionary regarding mad cow disease (in beef and in blood), fine particle air pollution, tobacco smoking, and terrorism. In our quantitative sample of 100 risks, by far the most common pattern (accounting for a third of the risks) is that the US and Europe were equally precautionary over the past four decades. Patterns reflecting a difference but no change in the direction of relative precaution were also common, accounting for about 20 percent of the risks. These unchanging cases are almost evenly divided between the cases in which Europe appears to have been more precautionary over the entire period and the cases in which the US appears to have been more precautionary over the entire period. Of the remaining cases in which there was a change in relative precaution, the change was slightly more often toward greater relative precaution in Europe, but almost as many cases showed the opposite result. Only five percent of the cases in our quantitative sample exhibited Vogel's "flip-flop" pattern (see Chapter 15 in Wiener et al. $2011^{32}$ ). ${ }^{33}$

Our causal explanations also differ. Voge $^{34}$ attributes his claimed shift in transatlantic precaution to changing public preferences, changing leadership preferences, and changing criteria for policymaking. Yet given our finding of no significant shift, his explanatory factors must be outweighed by other factors, or must be incorrect. ${ }^{35}$ For example, Vogel is demonstrably wrong that changes in the criteria for policymaking could explain the precautionary shift he asserts. He argues that US adoption of regulatory impact assessment (RIA) using cost-benefit-analysis helps explain his claim of reduced relative US precaution since the 1990s (on the premise that RIA is a check on precaution). But in reality, no major change in US criteria for policymaking occurred around 1990: the US adopted RIA at least a decade earlier in executive orders issued by Presidents Carter and Reagan, and reaffirmed it under President Clinton (whose executive order remains in force today); furthermore, the EU adopted RIA starting in 2001 and has strengthened it since then. These trends in policymaking criteria might actually imply the opposite of Vogel's claim - that is, if US adoption of RIA before 1990 restrained US precaution before 1990, and European adoption of RIA after 2001 restrained European precaution in recent years. More generally, based on our dozen case study chapters comparing precaution on specific risks, two chapters comparing precaution in risk information systems, and four chapters comparing explanatory factors, we 
find that the causes of the complex pattern are particular: they derive more from the specific crises and public responses, and the particular actors and institutions involved in each risk and each regulation, rather than from wholesale shifts in broad national approaches to regulation. And the development of RIA in the US followed by the adoption of RIA in the EU shows that, rather than two discrete blocs moving in opposite directions, the reality in at least some important respects is a process of borrowing, exchange and diffusion of policy ideas across these regulatory systems, yielding interconnectedness and hybridization. $^{36}$

\section{Assessing the two accounts}

How can two books on the same subject come to such different conclusions? Is there a way to assess and compare the validity of these studies? How can we build on these studies to come to increasingly valid conclusions not only about relative precaution but about regulation generally?

\section{Studying Regulatory Elephants}

Part of the answer to the first question can be found in the parable of the blind men and the elephant. This parable inspires empathy for scholars who study dynamic regulatory policies across legal systems. None of us can see the whole of regulation. This parable also explains why the typical approach to these studies leads scholars to conclude that regulatory elephants look variously like a snake, tree trunk, fan, or wall. When scholars grab handfuls of regulatory cases to study, it is not surprising that they frequently come to such different conclusions about the nature of regulatory elephants. And once scholars think that regulatory elephants look like a snake, tree trunk, fan, or wall, they continue to grope their way to parts of these elephants that feel familiar to them. Regulatory elephants are very large and have parts of all kinds in sufficient abundance to provide seemingly inexhaustible evidence in support of diverse views of their nature.

Thus, studies of just the most visible or salient risks and regulatory policies are committing the error of sample selection bias, predictably leading to generalizations that mischaracterize the larger reality. Compounding this initial error, others then accept the mischaracterization when it accords with their prior positions or with familiar narratives - committing an error of confirmation bias. A catchy claim that confirms prior misimpressions may thereby gain favor, despite broader evidence to the contrary; meanwhile, studies showing the reality to be more complex often fail to gain favor where they do not correspond to prior positions or narratives. ${ }^{37}$ As reviewer Winn ${ }^{38}$ tellingly remarks, Vogel ${ }^{39}$ seeks to "impose a coherent narrative" on debates about precaution -a narrative that may be appealing, but as our book shows, is not supported by the evidence about actual policies.

These dynamics may explain Burgess' view ${ }^{40}$ that while our book has better evidence, he is still "inclined to side with Vogel's approach" because Vogel's claim better matches Burgess' feelings about the "character" of European precaution. He emphasizes that precaution is often "symbolic" politics about "identity," rather than concrete policy, a point on which we agree, and which could be the subject of a different study building on our work, as we suggest below. For the moment, it is important to emphasize, as we do in our book, that the "character" or "identity" of "symbolic politics" is not the same as actual policymaking. That is why we studied actual policies. That we found no significant shift to greater European precaution in actual policies is not belied by European political rhetoric favoring precaution; rather, it shows the disjunction between rhetoric and reality. Despite the rhetoric, the evidence indicates that real policies are moderated in practice, and real societies are selective in their application of precaution. We found important examples of greater US precaution, with their own political rhetoric about national identity (e.g. on terrorism).

Similarly, Winn ${ }^{41}$ finds Vogel's flip-flop story more congenial to her "feeling" than the more com-

\footnotetext{
36 See Wiener, Rogers, Hammitt and Sand, The Reality of Precaution supra note 2, chapter 20; Jonathan B. Wiener, "The Diffusion of Regulatory Oversight", in Michael A. Livermore and Richard L. Revesz (eds), The Globalization of Cost-Benefit Analysis in Environmental Policy (New York, NY: Oxford University Press, 2013), pp. 123-141.

37 For other examples of this pathology of catchy but faulty generalizations in research and public discourse, see Wiener, Rogers, Hammitt and Sand, The Reality of Precaution, supra note 2, chapter 1.

38 Winn, "Precautionary Schemes", supra note 10.

39 Vogel, The Politics of Precaution, supra note 1.

40 Burgess, "Missing the Wood for the Trees", supra note 9.

41 Winn, "Precautionary Schemes", supra note 10.
} 
plex depiction of the precautionary reality offered in our book, but concedes that her own view is "impressionistic" and "lacks ... rigor." She suggests that we protest too much, because she thinks Vogel never claimed that Europe has become more precautionary since 1990, yet Vogel ${ }^{42}$ makes just this claim, which we have reproduced above and which we also quote in our book. She fears that our book's "empiricism" is at odds with what she calls "humanism" (though she simply labels Vogel's historical account with that term, with no explanation of what it means or why one history is "humanist" and another is not). She complains that we cite too many references. We agree with Winn that our book is carefully empirical, which we see as a strength. We do not agree that our book is somehow at odds with humanism or history - our book is clearly just as much (as Vogel's) about the history of human choices, ideas, perceptions, and consequences; and our book says as much or more about the history of precaution in culture, art and literature than do other assessments of comparative regulation (we discuss, among others, Homer, Montaigne, Goethe, de Beaumarchais, Cooper, Wilde, Blake, La Rochefoucauld, Berlin, Delacroix, and Bruegel). Winn ${ }^{43}$ advocates reliance on "schemes" to make sense of the world; we do not deny the value of such mental models, but our point is that when they are based on a misreading of reality, they need to be revised and updated. She bases her own "scheme" of greater European precaution on her "personal experiences" living in Europe and on her study of "the Internet and electronic commerce." While our book

42 David Vogel, "Ships Passing in the Night: The Changing Politics of Risk Regulation in Europe and the United States", Working Paper 2001/16, Robert Schuman Centre for Advanced Studies, European University Institute, available on the Internet at <http://www.eui. eu/RSCAS/WP-Texts/01_16.pdf> (last accessed on 18 April 2013); David Vogel, "The Hare and the Tortoise Revisited: The New Politics of Consumer and Environmental Regulation in Europe", 33 British Journal of Political Science (2003), pp. 557-580; Vogel, The Politics of Precaution, supra note 1.

43 Winn, "Precautionary Schemes", supra note 10.

44 Burgess, "Missing the Wood for the Trees", supra note 9.

45 Durodié, "Precautionary Tales", supra note 11.

46 See Gary King, Robert O. Keohane, and Sidney Verba, Designing Social Inquiry: Scientific Inference in Qualitative Research (Princeton, NJ: Princeton University Press, 1994) on drawing inferences from case studies. For application of these standards to studies of regulation see Allan Mazur, True Warnings and False Alarms: Evaluating Fears about the Health Risks of Technology, 1948-1971 (Washington, DC: Resources for the Future, 2004) and Brendon Swedlow, "Review of Allan Mazur's 'True Warnings and False Alarms: Evaluating Fears about the Health Risks of Technology, 1948-1971", 8(4) Environmental Science and Policy (2005), pp. 236-269. is a collaboration of both European and American authors, and many of our contributors have lived in both places, we specifically discuss how personal experiences and focusing on one case can be misleading about the larger reality.

Both Burgess ${ }^{44}$ and Durodié ${ }^{45}$ assert that our book "misses the wood for the trees." But they are assuming that they know the forest and its movement. Our book shows that upon closer examination, the forest has not shifted; in reality, only a few trees have shifted in one direction, while other trees have shifted in the other direction, and most trees have stayed put. Marking a trail on just a few nearby trees, or grabbing a nearby handful of elephant, does not accurately characterize the larger reality. Claims of a wholesale shift in relative transatlantic precaution cannot be based on generalizations drawn from just a few salient examples.

Social science standards for assessing the validity of the two accounts

Evaluating two different detailed comparative and historical accounts requires more than resort to feelings or intuitions; it requires criteria for assessing social science. Standards of internal and external validity are helpful to social scientists in evaluating research. A study has internal validity if its findings are internally consistent, address confounding variables and the temporal sequence of cause and effect, and thus are credible for the case being studied. A study has external validity if its findings can be used to generalize to a broader class of cases. ${ }^{46}$ Here we will briefly assess internal validity and more extensively assess external validity, because differences in the external validity of the cases studied are the primary reason for the different conclusions of these two books.

Assessing the validity of the books' qualitative case study chapters

Books based on case studies typically have high internal validity and low external validity because the cases in these books usually are well executed but are selected in ways that prevent their findings from being generalized beyond the cases studied. The case study chapters in both of the two books reviewed here fit this general pattern in social science, because they 
are high quality, successful efforts to determine the relative regulatory precaution of the US and Europe in the cases studied, but these cases cannot be used to generalize about relative precaution. Neither set of case study chapters is representative of the larger universe of risk policies. But the fact that our larger array of case studies found diverse degrees of selective precaution in US and European risk regulation, with some cases of greater European precaution and some cases of greater US precaution, undermines Vogel's claim of a wholesale shift toward greater European precaution based on his set of case studies (though does not by itself prove a contrary trend).

Significant evidence for the high internal validity of the case study chapters in both books is provided by the fact that the books generally come to the same conclusions where they studied the same cases. Both books find greater European precaution since 1990 on beef hormones, genetically modified foods, climate change, and chemicals; and convergence on new drug approval. The books differ in their assessment of one case. In contrast to Vogel, we find that on mad cow disease (bovine spongiform encephalopathy, BSE), regulatory policies were more precautionary since 1990 in the US than in Europe - both as to imports of British beef, and especially regarding the risk of transmitting the human form, variant Creutzfeldt-Jacob Disease (vCJD), via blood donations. The highly stringent US FDA blood donation policy, officially titled "precautionary," was not discussed in Vogel's book (because, he says, it was not a "business-caused" risk and therefore was outside the "scope" of his study ${ }^{47}$ - even though hospitals and blood banks are businesses).

The low external validity of case study chapters hampers or negates Vogel's attempt to generalize about the broad categories of risk represented by his chapter headings: food safety and agriculture, air pollution, chemicals and hazardous substances, and consumer safety. Each of these chapters contains some risk case studies that exhibit Vogel's claimed flip-flop pattern, but because Vogel selected these cases without determining how representative they are of the larger category, they have low external validity with respect to generalizing about the category. The cases within Vogel's chapters are likely to be as unrepresentative of precautionary patterns in the chapter category as they are of US and European precautionary regulation in general. For example, when we examined the Food Safety and Agriculture category in our data set (described in the next paragraph), we found that the category included seven different precautionary patterns, only one of which was Vogel's flip-flop pattern. Meanwhile, other studies find wide variation in relative precaution within Europe ${ }^{48}$, further undermining claims of a European trend.

Assessing the validity of our quantitative study of relative precaution

Recognizing these challenges to the external validity of case study chapters, we endeavored to improve on the methodology of comparative regulatory studies. Our book includes an additional study for which cases were selected in a way to support valid generalizations. We identified a universe of 2,878 environmental, health, and safety risks from the literature on risks in the US and Europe over the period, and then drew a random sample of 100 of them to study. ${ }^{49}$ This sample allowed us to generalize to the universe of risk policies, and gives our study its claim to high external validity.

In our sample of 100 risks, we found no significant trend toward increased European relative precaution after 1990. The net trend we observed is of the same magnitude as if only about $5 \%$ of the risk regulations shifted from more precautionary in the US to more precautionary in Europe, and 95\% did not shift. And among the risks in our sample, we observed 12 patterns of relative precaution. The most common pattern was that the US and Europe regulated with equal precaution; one of the least common patterns was Vogel's "flip-flop" pattern. These findings corroborate the varied patterns of relative precaution found in our case study chapters, and suggest that the flip-flop pattern of Vogel's case study chapters is true of only a very small percentage $(5 \%)$ of the larger universe of cases. (Winn ${ }^{50}$ suggests that we employed "meta-analysis," but that is not what

\footnotetext{
47 Vogel, "Response to Jonathan B. Wiener and R. Daniel Kelemen", supra note 21.

48 Peter H. Sand, "The Precautionary Principle: A European Perspective", 6 Human and Ecological Risk Assessment (2000), pp. 445 458; Joakim Zander, The Application of the Precautionary Principle in Practice: Comparative Dimensions (Cambridge: Cambridge University Press, 2010).

49 See Swedlow, Kall, Zhou et al., "Theorizing and Generalizing abou Risk Assessment and Regulation through Comparative Nested Analysis of Representative Cases", supra note 33; Wiener, Rogers, Hammitt and Sand, The Reality of Precaution, supra note 2, chapter 15

50 Winn, "Precautionary Schemes", supra note 10.
} 
we did; a meta-analysis is an aggregate study of data from several prior studies, but we collected our own data and performed our own analysis.)

We expressly recognize (here and in our book) that this quantitative methodology has some limitations compared to qualitative case studies. That is why we used both methods, rather than just one or the other. For example, although we scored our sample of 100 for relative precaution in official regulatory standards, we were not able to deepen this analysis to study political context, degree of actual implementation, policy impacts, or other attributes (which we did explore in our case study chapters and cross-cutting chapters). Still, the advantage of the large-N quantitative sampling approach is that it has much higher external validity than do qualitative case studies: because the sample is an unbiased representation of the broader universe, it can support characterizations of general trends - which an unrepresentative selection of case studies cannot. Reviewer Maria Weimer ${ }^{51}$ commends our approach. Again, that is why we undertook both methods - qualitative and quantitative - because each offers advantages in understanding regulation.

Vogel $^{52}$ argues that the main difference between our books is that they examine different sets of cases. This is surprising because both books repeatedly say, including in the title of Vogel's book, that they are studying precautionary regulation of environmental, health, and safety risks in the US and Europe. In his introduction, however, Vogel says that his "focus is on a subset of risks, namely those that involve health, safety, and environmental risks caused by business". ${ }^{53}$ Subsequently he narrows his focus even further: "I confine my study to regulations that address consumer and environmental risks, primarily to public health and safety, and which are caused largely by the decisions of business firms". ${ }^{54}$ Thus he appears to exclude most cases of environmental

51 Weimer, "It's the Politics, Stupid", supra note 3.

52 Vogel, "Response to Jonathan B. Wiener and R. Daniel Kelemen", supra note 21; Vogel, "A More Sophisticated Understanding of the Politics of Precaution", supra note 4.

53 Vogel, The Politics of Precaution, supra note 1, on p. 18.

54 Vogel, "Response to Jonathan B. Wiener and R. Daniel Kelemen", supra note 21.

$55 \mathrm{Ibid}$; see also Vogel, The Politics of Precaution, supra note 1, p. 4. 56 Wiener, "The Politics of Precaution, and the Reality", supra note 35. risk that do not also pose public health and safety risks. And he excludes public health and safety risks that are not largely "caused by business." Moreover, he claims that he is only interested in studying the regulation of important risks of these kinds, where importance is "measured by their costs, political salience, or the magnitude of the harms they are attempting to avoid or ameliorate" ${ }^{55}$ Thus, he claims that it is among the subset of important, businesscaused health and safety risks that the flip-flop pattern of precaution dominates.

As Wiener discusses further elsewhere ${ }^{56}$, Vogel's scope limitation to "caused by business" appears arbitrary, excluding many important risks that happen to exhibit greater US precaution (for example, Vogel says it does not include terrorism, or mad cow disease in blood); is difficult to implement, because many risks are caused by combinations of business and other factors and cannot be distinguished as simply caused or not caused by business; and even if applied, would actually include risks that Vogel supposes it excludes (such as mad cow disease in blood, where causal factors include businesses in farming, animal feed, food processing, blood banks, and hospitals). Nevertheless, even though Vogel has either not given reasons or has offered what in our view are inadequate reasons for limiting the scope of his study to important, business-caused health and safety risks, we have made a preliminary attempt to study this subset of risks within our universe of risks, as discussed below. Our finding from this preliminary re-analysis is that the flip-flop pattern remains a minor pattern even within Vogel's subset of risks.

It is important to emphasize that Vogel has not studied a representative sample of even the subset he claims to characterize. Had Vogel constructed a universe of his subset, and randomly selected cases from it to study, he would have the same claim to external validity as we do. But he did not do this. What he did instead is gather some cases of a particular kind - i.e., important, business-caused health and safety risks that he found salient - without any way to know how representative these cases are of others of this kind that he did not study. While this may be a standard way to assemble books of cases in regulatory studies, there is no way around the fact that cases selected in this manner have low or no external validity. As discussed above, this point holds as well for each of the four major categories of cases represented by Vogel's four case study chapters: there is no way to know if the various cases studied within 
these chapters are representative of the chapter category. This basic point holds as well for Vogel's chapter categories: there is no way to know how representative these categories are of other categories, nor how many other categories there are. Our study, by contrast, took a random, representative sample from our best effort to collect the universe of 2,878 risks, inductively subdivided the universe and our sample into 18 categories and 92 subcategories of risks, and found great diversity of regulatory patterns within as well as across these categories.

Our preliminary study of the subset of "important, business-caused health and safety risks" (Vogel's scope) in our own random sample of 100 shows that Vogel's flip-flop pattern is only a minor pattern of transatlantic precaution even within that subset. First, 95 of our 100 risks involve threats to health or safety or both; 45 involve threats to health, safety, and the environment; and only two involve threats solely to the environment. ${ }^{57}$ Based on a preliminary attempt to code our 100 risks, at least 80 of them are caused by business, either directly or indirectly, and these 80 cases all fall within the 95 health and/or safety risks in our sample. Meanwhile, the five flip-flop cases in our sample all fall within these 80 business-caused cases, making them six percent of this subset of cases (rather than five percent of the 100 cases). Thus, focusing on the business-caused subset of health and safety risks in our sample barely increases the very small proportion of cases that exhibit the flip-flop pattern.

Vogel $^{58}$, along with Burgess ${ }^{59}$, conjectures that if our sample were weighted for the "importance" of each risk, it would show a greater shift to relative European precaution since 1990. They offer no evidence for this conjecture. Our qualitative case studies indicate the opposite: arguably the most "important" risks in both books (measured by the magnitude of health and safety burden in mortality and morbidity) are tobacco and fine particle air pollution, both of which exhibit greater US precaution since 1990 (as does another potentially highly important emerging risk, terrorism; yet climate change points the other way). In our quantitative sample, the 5 or $6 \%$ of risks trending toward European precaution would have to be many times more "important" than the other 94 or $95 \%$ of risks not trending toward greater European precaution, for the net trend to just barely validate Vogel's conjecture; this is highly implausible. We are therefore confident that neither the qualitative case studies nor the quantitative data analysis support Vogel's conjecture.

\section{Contributions to the study of relative precaution and regulation}

Both books significantly advance the study of relative precaution and of regulation more generally. The case studies of both books advance regulatory studies by developing and testing explanations for the patterns found in these cases. They thus provide more robust tests of various explanations than studies that test their explanations against fewer cases. As a result of these tests, the books are able to rule out some explanations. Thus, Vogel and we agree that static conceptions of national political culture $e^{60}$ , or families of law or legal origins ${ }^{61}$, cannot account for the dynamic precautionary patterns we have observed. Vogel also rules out a variety of other explanations for the flip-flop pattern. Vogel argues that three factors explain his claimed shift: changing public preferences, changing leadership preferences, and changing criteria for policy (see discussion above). Critiques of Vogel's explanations ${ }^{62}$, however, have led Vogel to add the additional explanatory factor of party system differences ${ }^{63}$. Further research will be necessary to determine whether these factors are sufficient to explain the very large percentage of risks that do not exhibit the flip-flop pattern. Because the data do not indicate a significant shift toward greater European relative precaution, Vogel's factors explaining such a shift must have been outweighed by other factors - notably, factors that instead drive what we find, namely a more complex pattern of issue-specific policy choice and selective precaution on both sides of the Atlantic.

57 See Table 15.2 in Swedlow, Kall, Zhou et al., "A Quantitative Comparison of Relative Precaution in the United States and Europe, 1970-2004", supra note 24.

58 Vogel, "A More Sophisticated Understanding of the Politics of Precaution", supra note 4.

59 Burgess, "Missing the Wood for the Trees", supra note 9.

60 David Vogel, National Styles of Regulation: Environmental Policy in Great Britain and the United States (Ithaca, NY: Cornell University Press, 1986).

61 Zweigert and Kötz, An Introduction to Comparative Law, supra note 19; La Porta, Lopez-de-Silanes and Shleifer, "The Economic Consequences of Legal Origins", supra note 20.

62 R. Daniel Kelemen, "Commentary on Vogel's The Politics of Precaution" 7(2) Regulation \& Governance (2013), pp. 266-270; Wiener, "The Politics of Precaution, and the Reality", supra note 35.

63 Vogel, "Response to Jonathan B. Wiener and R. Daniel Kelemen", supra note 21. 
Our book also advances the methodology of regulatory studies by constructing a universe of environmental, health, and safety risks and by using a representative sample of that universe to provide a quantitative account of the relative regulatory precaution of the US and Europe with a plausible claim to external validity. Reviewer Weimer ${ }^{64}$ highlights the methodological advance offered by this approach. This universe and sample represent significant resources for regulatory scholars. One of us is building a collaborative research network to collect additional information on these cases to answer a variety of questions and test a variety of regulatory theories. ${ }^{65}$ To accelerate data collection and theory testing, we and collaborators are studying a smaller representative sample of 30 risks, using a mixed-method approach called comparative nested analysis. ${ }^{66}$ This additional research can be used to test alternative

64 Weimer, "'It's the Politics, Stupid'", supra note 3.

65 Swedlow, Kall, Zhou et al, "Theorizing and Generalizing about Risk Assessment and Regulation through Comparative Nested Analysis of Representative Cases", supra note 33.

66 Evan S. Lieberman, "Nested Analysis as a Mixed-Method Strategy for Comparative Research", 99 American Political Science Review (2005), pp. 435-452.

67 Vogel, "A More Sophisticated Understanding of the Politics of Precaution", supra note 4 .

68 Rose-Ackerman, "Precaution, Proportionality, and Cost/Benefit Analysis: False Analogies", supra note 5.

69 Wiener, Rogers, Hammitt and Sand, The Reality of Precaution, supra note 2, chapter 20.

70 Burgess, "Missing the Wood for the Trees", supra note 9.

71 Durodié, "Precautionary Tales", supra note 11. explanations for relative precaution, as well as a variety of other explanations for other regulatory phenomena, an enterprise we are pleased to learn that Vogel $^{67}$ also endorses.

Our risk universe, sample, and methods could be used, for example, to answer some questions posed by three of our reviewers. Rose-Ackerman ${ }^{68}$ would have liked both books to investigate and compare the US and Europe with respect to their use of different approaches to precaution and to study how the proportionality principle, cost-benefit analysis, and regulatory impact assessment relate to precautionary regulation in these polities. Our book begins to do so in its concluding chapter ${ }^{69}$, in which we report on the growing use of these approaches in the European as well as in US regulation. She is also interested in better understanding which values are embedded in choices among risk analytic techniques and how values are otherwise brought to bear in risk assessment and regulation. These worthwhile objectives could be investigated in our sample of cases in the ongoing collaborative study just mentioned. Similarly, further study of these cases would help furnish better answers to Burgess ${ }^{70}$ questions about how risk regulation is connected to historical trends and discontinuities in politics, and how precautionary regulation relates to what he sees as a crisis of identity in Europe. Likewise, Durodié's ${ }^{71}$ desire to understand the extent to which and reasons why transatlantic political elites perceived that a precautionary flipflop was underway could be aided by studying our representative sample of cases. In other words, there are many opportunities here to study regulatory elephants in better ways. 